\title{
An assessment of the vulnerability of carotid plaques: a comparative study between intraplaque neovascularization and plaque echogenicity
}

\author{
Yangyang Zhou ${ }^{1+}$, Yingqi Xing ${ }^{3+}$, Yan $\mathrm{Li}^{2}$, Yang Bai ${ }^{2}$, Ying Chen ${ }^{3}$, Xiaofeng Sun ${ }^{2}$, Yingqiao Zhu ${ }^{2}$ and Jiang $\mathrm{Wu}^{{ }^{* *}}$
}

\begin{abstract}
Background: Carotid plaque echolucency as detected by Color Doppler ultrasonography (CDUS) has been used as a potential marker of plaque vulnerability. However, contrast-enhanced ultrasound (CEUS) has recently been shown to be a valuable method to evaluate the vulnerability and neovascularization within carotid atherosclerotic plaques. The aim of this study was to compare CEUS and CDUS in the assessment of plaque vulnerability using transcranial color Doppler (TCD) monitoring of microembolic signals (MES) as a reference technique.

Methods: A total of 46 subjects with arterial stenosis ( $\geq 50 \%$ ) underwent a carotid duplex ultrasound, TCD monitoring of MES and CEUS (SonoVue doses of $2.0 \mathrm{~mL}$ ) within a span of 3 days. The agreement between the CEUS, CDUS, and MES findings was assessed with a chi-square test. A p-value less than 0.05 was considered statistically significant.
\end{abstract}

Results: Neovascularization was observed in 30 lesions (44.4\%). The vascular risk factors for stroke were similar and there were no age or gender differences between the 2 groups. Using CEUS, MES were identified in 2 patients (12.5\%) within class 1 (non-neovascularization) as opposed to 15 patients (50.0\%) within class 2 (neovascularization) $(p=0.023)$. CDUS revealed no significant differences in the appearance of the MES between the 2 groups (hyperechoic and hypoechoic) ( $p=0.237$ ).

Conclusion: This study provides preliminary evidence to suggest that intraplaque neovascularization detected by CEUS is associated with the presence of MESs, where as plaque echogenicity on traditional CDUS does not. These findings argue that CEUS may better identify high-risk plaques.

Keywords: Contrast-enhanced ultrasound (CEUS), Plaque vulnerability, Monitoring of microembolic signals (MES), Color Doppler ultrasonography (CDUS)

\section{Background}

Internal carotid artery (ICA) disease is frequently observed in ischemic stroke patients. Histological and imaging studies [1-3] have demonstrated that stroke is dependent on the degree of stenosis and the morphological features of the plaque, such as ulcers or fissures. These morphological features can cause a rupture [4] of the plaque and

\footnotetext{
* Correspondence: yyangyangzhou@gmail.com

${ }^{\dagger}$ Equal contributors

'Department of Neurology, The First Norman Bethune Hospital of Jilin University, Xinmin Street 71\#, 130021, Chang Chun, China

Full list of author information is available at the end of the article
}

result in embolization, which is known as "vulnerability". All of these factors should be considered when developing an accurate diagnostic and preventive approach aimed at risk stratification and treatment planning to reduce the incidence and severity of acute cerebrovascular disease. Color Doppler ultrasonography (CDUS) has been the the screening test of choice for assessing carotid atherosclerosis. Echolucency of the Carotid plaque is a valuable marker of the plaque vulnerability [5-7].

However, recently several studies have confirmed the feasibility of using contrast-enhanced ultrasound (CEUS) for the evaluation of neovascularization within carotid

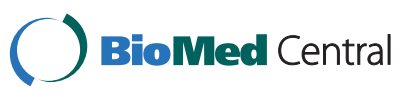


atherosclerotic plaques. Furthermore, this technique may also be used to assess the vulnerability of carotid plaques [8-11]. Levovist is an ultrasound contrast agent (BR1; Bracco SpA, Milan, Italy; Definity, Lantheus Medical Imaging) that enables the optimization of technically difficult explorations using a Doppler signal of sufficient intensity and improves the detection of minimal flow rates and slow velocities in severe cases of stenosis.

Previous studies [12,13] demonstrate that echolucent plaques tend to have greater contrast enhancement compared to echogenic plaques. Echolucent plaques are known to exhibit a larger number of vulnerable pathological features and correlate with a higher risk of cerebrovascular events [14]. However, studies to determine the most accurate technique for assessing plaque vulnerability have been limited. The aim of our study was to compare CEUS-detected neovascularization with plaque morphology on CDUS with regards to their correlation with MESs.

\section{Materials and methods}

Patient group and informed consent

This study was approved by the local ethics committee and written informed consent was obtained from all patients. The following data was recorded from the patient: age, sex, previous symptoms (Transient ischemic attacks (TIA), dysphasia, single limb paresis and amaurosis fugax) and co-morbid risk factors (hypertension, hyperlipidemia, diabetes and smoking habits) (Table 1 and Table 2). Both asymptomatic and symptomatic patients were included.

Between March 2011 and March 2012, 54 subjects with arterial stenosis $(\geq 50 \%)$ underwent CDUS $\left(\mathrm{PSV}_{\mathrm{ICA}} \geq 125 \mathrm{~cm} / \mathrm{s}\right.$ and visible plaque [15]) at the First Norman Bethune Hospital of Jilin University. In addition, TCD monitoring of MES and CEUS examinations were performed within 3 days by two independent researchers (Y.L. and Y.B.). MES monitoring was performed by two

Table 1 Differences in the clinical characteristics of class 1 (non-neovascularization) and class 2 (neovascularization) determined by CEUS

\begin{tabular}{llll}
\hline & $\begin{array}{l}\text { Class 1 } \\
(\mathbf{n = 1 6 )}\end{array}$ & $\begin{array}{l}\text { Class 2 } \\
(\mathbf{n = 3 0})\end{array}$ & P-value \\
\hline Age (years), mean \pm SD & $64.38 \pm 11.32$ & $61.50 \pm 6.26$ & 0.186 \\
Men, n (\%) & $16(100 \%)$ & $27(90 \%)$ & 0.542 \\
Neurological symptoms*, n (\%) & $6(37.5 \%)$ & $18(60 \%)$ & 0.217 \\
Hypertension, n (\%) & $9(56.3 \%)$ & $13(43.3 \%)$ & 0.538 \\
Diabetes mellitus, n (\%) & $3(18.8 \%)$ & $9(30.0 \%)$ & 0.498 \\
Hypercholesterolemia, n (\%) & $9(56.3 \%)$ & $18(60.0 \%)$ & 1.000 \\
Current smoker, n (\%) & $8(50.5 \%)$ & $19(63.3 \%)$ & 0.531 \\
\hline
\end{tabular}

*Neurological symptoms include previous transient ischemic attacks (TIA), dysphasia, single limb paresis, and amaurosis fugax.
Table 2 Differences in the clinical characteristics of group 1 (hyperechoic) and group 2 (hypoechoic) determined by CDUS

\begin{tabular}{llll}
\hline & $\begin{array}{l}\text { Group 1 } \\
\text { (n= 28) }\end{array}$ & $\begin{array}{l}\text { Group 2 } \\
\text { (n= 18) }\end{array}$ & P-value \\
\hline Age (years), mean 土 SD & $62.22 \pm 6.31$ & $62.96 \pm 9.54$ & 0.456 \\
Men, n (\%) & $26(92.9 \%)$ & $17(94.4 \%)$ & 1.000 \\
Neurological symptoms*, n (\%) & $16(57.1 \%)$ & $8(44.4 \%)$ & 0.295 \\
Hypertension, n (\%) & $17(60.7 \%)$ & $10(55.6 \%)$ & 0.767 \\
Diabetes mellitus, n (\%) & $8(28.5 \%)$ & $5(27.8 \%)$ & 1.000 \\
Hypercholesterolemia, n (\%) & $15(53.6 \%)$ & $12(66.7 \%)$ & 0.541 \\
Current smoker, n (\%) & $18(64.3 \%)$ & $13(72.2 \%)$ & 0.749 \\
\hline
\end{tabular}

*Neurological symptoms include previous transient ischemic attacks (TIA), dysphasia, single limb paresis, and amaurosis fugax.

neuroradiologists (Y-Q.X and Y.C.). Patients with any of the following conditions were excluded: [1] complete ICA occlusion or $<50 \%$ stenosis based on CDUS; [2] evidence of cardioembolism, such as atrial fibrillation, mechanical valve replacement, left atrial or left ventricular thrombus, bacterial endocarditis, or recent myocardial infarction; [3] ipsilateral stenosis of the middle cerebral artery (MCA) or intracranial internal carotid artery in the TCD; [4] a poor temporal window; or [5] poor image quality of the vessel wall or lumen. Therefore, data from remaining 46 patients (43 male and 3 women) with satisfactory image quality were analyzed.

\section{Color Doppler ultrasonography (CDUS)}

We used an ultrasound Philips iU22 system (Philips Healthcare Solutions, Bothell, WA, USA) equipped with an L-9-3 linear-array transducer. The instrument was operated by 2 experienced readers ( $\mathrm{Y}-\mathrm{YZ}$ and $\mathrm{YC}$ ), who were blinded to all of the clinical laboratory findings and other imaging data.

The maximal thickness of the lesion located at the bifurcation and proximal to the bifurcation was assessed as a continuous variable and measured from the anterior, lateral and cross-sectional scanning plane using a longitudinal image from the media-adventitia to the intimalumen boundaries. The B-mode settings were adjusted to optimize the quality of the gray-scale images and the pulse repetition frequency (PRF) used with the color Doppler flow imaging was adjusted according to the flow velocity.

The characteristics of the plaques were described according to the modified Gray Weale classification [16]. The lesion echogenicity was classified into group 1 (uniformly hyperechoic or predominantly ( $>50 \%$ ) hyperechoic) or group 2 (uniformly hypoechoic or predominantly $(>50 \%)$ hypoechoic). All results were agreed upon by at least two experienced neuroradiologists. 


\section{Contrast-enhanced ultrasound (CEUS)}

A contrast-enhanced ultrasound examination was performed using an Acuson Sequoia 512 imaging system (Siemens, Mountain View, CA, USA) with a $2-\mathrm{MHz}$ transducer by 2 experienced readers (Y.B. and Y.L.), who were blinded to all of the clinical laboratory findings and other imaging data. Disagreements between the readers were settled by a consensus reading. The patients were placed in a supine position. A 5-mL solution was prepared from $1 \mathrm{~mL}$ of the activated contrast agent (BR1; Bracco SpA, Milan, Italy; Definity, Lantheus Medical Imaging) diluted in $4 \mathrm{~mL}$ of saline. An initial bolus injection was quickly performed. The second injection was performed slowly and was followed by $5 \mathrm{~mL}$ of normal saline to flush out the contrast from the vein. The time gap between the injections was approximately 3 minutes. The contrast-enhanced ultrasound imaging application included a low mechanical index (0.07) to avoid early bubble destruction and harmonics with pulse inversion to optimize the depiction of the IV contrast agent and minimize echoes from the surrounding tissues. Cine loops were recorded for 5 heart cycles, starting from the time in which the contrast agent could be observed in the carotid lumen. Following the infusion of the ultrasound contrast agent, the lumen of the carotid artery was enhanced, resulting in visualization of enhanced plaque luminal morphology. The presence of blood flow "activity" was identified on the basis of the dynamic movement of the echogenic reflectors (microspheres) in the intraplaque microvessels.

Intraplaque neovascularization (contrast agent enhancement) was categorized using a modified grading scale and classified as class 1 (non-neovascularization) or class 2 (neovascularization).

\section{TCD ultrasound examination}

MES monitoring was performed by two experienced neuroradiologists ( $\mathrm{Y}-\mathrm{YZ}$ and $\mathrm{YC}$ ) with a TCD machine (EME TC8080; Nicolet, Madison, WI, USA) with a 2$\mathrm{MHz}$ transducer. The patients were placed in the supine position and bilateral MCA recordings were obtained for 30 minutes at a depth of $44-60 \mathrm{~mm}$. The MES were identified on the basis of Doppler waves obtained from the MCA ipsilateral to the side of the ICA stenosis. The following definitions for emboli signals were used: typical, visible, and audible (click, chirp, whistle). Shortduration, high-intensity signals within the Doppler flow spectrum occurred at random intervals during the cardiac cycle. Signals were defined at $6 \mathrm{~dB}$ above the background threshold on the basis of standard consensus criteria described in previous studies. The presence of MES was assessed by an independent expert reader (Y-QX), who was blinded to all of the clinical laboratory findings and other imaging data.

\section{Database and statistical analysis}

All of the data were analyzed with SPSS 17.0. The results are expressed as the mean value and standard deviation (SD) for each measurement. Categorical variables were assessed using the chi-square test. A $p$-value of less than 0.05 was considered statistically significant.

\section{Results}

Forty-six patients (43 men and 3 women) with satisfactory image quality were analyzed. The differences in the clinical characteristics are reported in Table 1 and Table 2.

CEUS revealed neovascularization in 30 patients (44.4\%). The stroke vascular risk factors were similar between groups, and there were no age or gender differences between the 2 classes (Table 1). MES were observed in 2 patients (12.5\%) within class 1 (non-neovascularization) and in 15 patients $(50.0 \%)$ within class 2 (neovascularization) $(p=0.0230)$ (Table 3, Figure 1).

Using CDUS, 28 patients were identified in group 1 (hyperechoic), and 18 were identified in group 2 (hypoechoic). Stroke vascular risk factors, age and gender were similar between the 2 groups (Table 2). Moreover, no significant differences were observed in the appearance of the MES between the 2 groups $(p=0.2368)$ (Table 4$)$.

\section{Discussion}

In this study, we examined the relationship between CEUS and CDUS characteristics of the carotid plaque with special reference to MES. We found an association between MES monitoring and the degree of contrast-agent enhancement using ultrasound imaging $(p=0.0230)$. However, we did not observe a significant association between the MES results and CDUS properties $(p=0.2368)$. Although plaque echolucency is a marker of high-risk lesions (rupture prone plaques), our findings indicate that CEUS appears to be more accurate at assessing plaque vulnerability.

CDUS has replaced digital subtraction angiograph for the diagnosis of carotid stenosis, in part because CDUS provides enhanced definition of plaque morphology $[17,18]$. Several studies $[5,14,19-21]$ have demonstrated that echogenic plaques are well-established markers of high-risk lesions and are associated with the presence of neurological symptoms and the development of future strokes in previously symptomatic individuals. Furthermore, echogenic plaques also coincide with the occurrence of acute coronary syndromes. Several studies have

Table 3 Comparison of the MES measurements (mean D) of class 1 (non-neovascularization) and class 2 (neovascularization) determined by CEUS

\begin{tabular}{llll}
\hline & Class $\mathbf{1}(\mathbf{n}=\mathbf{1 6})$ & Class $\mathbf{2}(\mathbf{n}=\mathbf{3 0})$ & P-value \\
\hline MES $(\mathrm{z}), \mathrm{n}(\%)$ & $2(12.5)$ & $15(50.0)$ & 0.023 \\
\hline
\end{tabular}



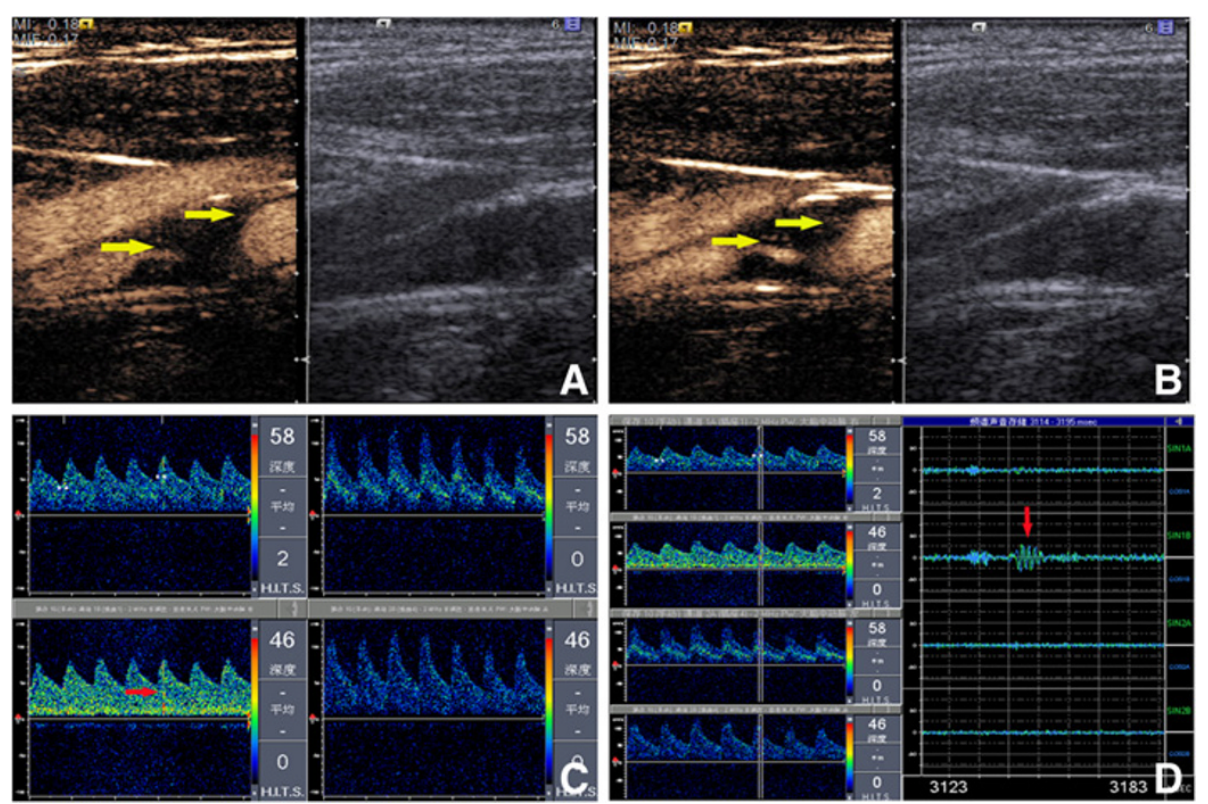

Figure 1 A 56 year-old female patient with TIA. CEUS (A and B) detected 2 consecutive frames of intra-plaque neovascularization (yellow arrow). MES (red arrow) was detected in the ipsilateral middle cerebral artery (C and $\mathbf{D})$.

reported [22-26] that echogenic plaques are prone to rupture due to their increased lipid content and macrophage density as well as intraplaque hemorrhage; in addition, increased plasma and low-density lipoprotein cholesterol levels make them vulnerable and prone to ulceration and embolization.

Neovascularization is considered an important feature in plaque development and vulnerability and is triggered by inflammation and hemorrhage $[8,27,28]$. The vulnerability of the neovasculature to rupture increases the risk of cerebral emboli. Several pathological studies [28-30] have confirmed that plaque rupture is strongly associated with the presence and degree of neovascularization within the plaque.

Intraplaque microvessels (angiogenesis) within the atherosclerotic lesions arise mainly from the adventitial vasa vasorum. Extension of the vasa vasorum to the full thickness of the media and intima of atherosclerotic segments represents pathological neovascularization, which is stimulated by plaque hypoxia, reactive oxygen species, hypoxia-inducible factor signaling and inflammation [31,32].

Feinstein et al. [33] and Assaf Hoogi et al. [11] compared the results of CEUS with histological characteristics. Their findings revealed that contrast enhancement

Table 4 Comparison of the MES measurements (mean D) of group 1 (hyperechoic) and group 2 (hypoechoic) determined by CDUS

\begin{tabular}{llll}
\hline & Group $\mathbf{1}(\mathbf{n}=\mathbf{2 8})$ & Group 2 $(\mathbf{n}=\mathbf{1 8})$ & P-value \\
\hline $\operatorname{MES}(\mathrm{z}), \mathrm{n}(\%)$ & $12(42.9)$ & $5(27.8)$ & 0.237 \\
\hline
\end{tabular}

within the plaque is correlated with a higher number of microvessels. The studies of Staub et al. [10] and Faggioli et al. [34] have indicated the feasibility of using CEUS to depict neovascularization within the carotid plaque to facilitate the further stratification of the risk of rupture of carotid artery lesions. Thus, CEUS has been proposed as a method to preoperatively identify vulnerable plaques.

Consistent with the data obtained in previous reports $[12,13]$, neovascularization visualized using CEUS is correlated with the morphological features of plaque vulnerability, including echogenic plaques, as a marker of high risk lesions.

Coli et al. [12] reported that carotid plaque contrast agent enhancement correlated with echogenic plaques $(p=0.001)$ and is associated with the histological density of neovessels. Interestingly, intraplaque neovascularization in CEUS images correlated well with histological microvessel density rather than plaque echolucency suggesting that low echo intensity is not correlated with the histological density of the vasa vasorum. Thus CEUS is a more specific imaging modality to identify highly vascularized and inflamed vulnerable lesions as compared to standard CDUS in isolation.

Our observations strongly indicate a positive relationship between neovascularization in plaques and MES while there is a poor correlation between plaque echolucency and MES. Embolism is an important mechanism of cerebral infarcts in patients with ICA stenosis [35]. The detection of cerebral microembolisms by transcranial Doppler sonography may permit the definition of a 
high-risk subgroup among patients with asymptomatic high-grade internal carotid artery stenosis [36]. To the best of our knowledge, this is the first study to explore neovascularization in stroke patients with ICA stenosis using MES and CEUS.

There were some limitations in this study. The first limitation was that the pilot study was conducted with a small sample size. Second, we used a semi-quantitative approach to evaluate the contrast-agent enhancement; however, this limitation does not alter our observations or conclusions. This quantitative method needs to be further investigated. Finally, several patients could not be examined because of an inadequate insonation window during the TCD monitoring that prevented further analysis. Future studies in larger populations are required to validate the results of the present study. Moreover, prospective clinical studies are also needed to evaluate the use of contrast-enhanced ultrasound imaging of plaque neovascularization to assess the risk of cerebrovascular events and to monitor the effects of anti-atherosclerotic therapies.

\section{Conclusions}

Intraplaque neovascularization detected by CEUS but not plaque echolucency is correlated with MES, suggesting that CEUS may provide valuable information about plaque risk stratification and may be an accurate method for assessing vulnerable plaques beyond the echogenicity of CDUS.

\section{Competing interests}

The authors declare that there are no competing interests.

\section{Authors' contributions}

$Y Z$ and $Y X$ participated in the design of the study, performed the statistical analysis, participated in the sequence alignment, CDUS, and MES studies, and drafted the manuscript. YL, YB, XS, and $Y Z$ performed the CEUS studies. YC participated in the CDUS and MES studies. YX and JW developed the concept of the study and participated in its design and coordination. All authors have read and approved the final manuscript.

\section{Acknowledgements \\ This work was performed at First Norman Bethune Hospital of Jilin University and was funded by the Jilin Provincial Health Department of China. The authors declare that they have no competing interests. Unrelated to this study, Dr. Xing receives/received research funding from the National Natural Science Foundation of China (Grant No. 81100855 and 81000490). The Medical Ethical Committee of Jilin University gave the approval for the study.}

\section{Author details}

'Department of Neurology, The First Norman Bethune Hospital of Jilin University, Xinmin Street 71\#, 130021, Chang Chun, China. ${ }^{2}$ Center for Abdominal Ultrasound, The First Norman Bethune Hospital of Jilin University, Chang Chun, China. ${ }^{3}$ Center for Neurovascular Ultrasound, The First Norman Bethune Hospital of Jilin University, Chang Chun, China.

Received: 15 November 2012 Accepted: 14 March 2013

Published: 28 March 2013

\section{References}

1. Fisher M, Paganini-Hill A, Martin A, Cosgrove M, Toole JF, Barnett HJ, Norris J: Carotid plaque pathology: thrombosis, ulceration, and stroke pathogenesis. Stroke 2005, 36:253-257.

2. Kolodgie FD, Gold HK, Burke AP, Fowler DR, Kruth HS, Weber DK, Farb A, Guerrero $L$, Hayase M, Kutys R, Narula J, Finn AV, Virmani R: Intraplaque hemorrhage and progression of coronary atheroma. N Engl J Med 2003, 349:2316-2325

3. Nandalur KR, Baskurt E, Hagspiel KD, Phillips CD, Kramer CM: Calcified carotid atherosclerotic plaque is associated less with ischemic symptoms than is noncalcified plaque on MDCT. AJR Am J Roentgenol 2005, 184:295-298.

4. Naghavi M, Libby P, Falk E, Casscells SW, Litovsky S, Rumberger J, Badimon J, Stefanadis C, Moreno P, Pasterkamp G, Fayad Z, Stone PH, Waxman S, Raggi P, Madjid M, Zarrabi A, Burke A, Yuan C, Fitzgerald PJ, Siscovick DS, de Korte CL, Aikawa M, Juhani Airaksinen KE, Assmann G, Becker CR, Chesebro JH, Farb A, Galis ZS, Jackson C, Jang IK, Koenig W, Lodder RA, March K, Demirovic J, Navab M, Priori SG, Rekhter MD, Bahr R, Grundy SM, Mehran R, Colombo A, Boerwinkle E, Ballantyne C, Insull W Jr, Schwartz RS, Vogel R, Serruys PW, Hansson GK, Faxon DP, Kaul S, Drexler H, Greenland P, Muller JE, Virmani R, Ridker PM, Zipes DP, Shah PK, Willerson JT: From vulnerable plaque to vulnerable patient: a call for new definitions and risk assessment strategies: Part I. Circulation 2003, 108:1664-1672.

5. Seo Y, Watanabe S, Ishizu T, Moriyama N, Takeyasu N, Maeda H, Ishimitsu T, Aonuma K, Yamaguchi I: Echolucent carotid plaques as a feature in patients with acute coronary syndrome. Circ J 2006, 70:1629-1634.

6. Gronholdt ML, Nordestgaard BG, Schroeder TV, Vorstrup S, Sillesen H: Ultrasonic echolucent carotid plaques predict future strokes. Circulation 2001, 104:68-73.

7. Ogata T, Yasaka M, Wakugawa Y, Kitazono T, Okada Y: Morphological classification of mobile plaques and their association with early recurrence of stroke. Cerebrovasc Dis 2010, 30:606-611.

8. Huang PT, Chen CC, Aronow WS, Wang XT, Nair CK, Xue NY, Shen X, Li SY, Huang FG, Cosgrove D: Assessment of neovascularization within carotid plaques in patients with ischemic stroke. World J Cardiol 2010, 2:89-97.

9. Caplice NM, Martin K: Contrast-enhanced ultrasound and the enigma of plaque neovascularization. JACC CardiovasC Imaging 2010, 3:1273-1275.

10. Staub D, Patel MB, Tibrewala A, Ludden D, Johnson M, Espinosa P, Coll B, Jaeger KA, Feinstein SB: Vasa vasorum and plaque neovascularization on contrast-enhanced carotid ultrasound imaging correlates with cardiovascular disease and past cardiovascular events. Stroke 2010, 41:41-47.

11. Hoogi A, Adam D, Hoffman A, Kerner H, Reisner S, Gaitini D: Carotid plaque vulnerability: quantification of neovascularization on contrast-enhanced ultrasound with histopathologic correlation. AJR Am J Roentgenol 2011, 196:431-436.

12. Coli S, Magnoni M, Sangiorgi G, Marrocco-Trischitta MM, Melisurgo G, Mauriello A, Spagnoli L, Chiesa R, Cianflone D, Maseri A: Contrast-enhanced ultrasound imaging of intraplaque neovascularization in carotid arteries: correlation with histology and plaque echogenicity. J Am Coll Cardiol 2008, 52:223-230.

13. Staub D, Partovi S, Schinkel AF, Coll B, Uthoff H, Aschwanden M, Jaeger KA, Feinstein SB: Correlation of carotid artery atherosclerotic lesion echogenicity and severity at standard US with intraplaque neovascularization detected at contrast-enhanced US. Radiology 2011, 258:618-626.

14. Mathiesen $\mathrm{EB}$, Bonaa $\mathrm{KH}$, Joakimsen $\mathrm{O}$ : Echolucent plaques are associated with high risk of ischemic cerebrovascular events in carotid stenosis: the tromso study. Circulation 2001, 103:2171-2175.

15. Grant EG, Benson CB, Moneta GL, Alexandrov AV, Baker JD, Bluth El, Carroll BA, Eliasziw M, Gocke J, Hertzberg BS, Katanick S, Needleman L, Pellerito J, Polak JF, Rholl KS, Wooster DL, Zierler RE: Carotid artery stenosis: grayscale and Doppler US diagnosis-Society of Radiologists in Ultrasound Consensus Conference. Radiology 2003, 229:340-346.

16. Geroulakos G, Ramaswami G, Nicolaides A, James K, Labropoulos N, Belcaro G, Holloway M: Characterization of symptomatic and asymptomatic carotid plaques using high-resolution real-time ultrasonography. Br J Surg 1993, 80:1274-1277.

17. Degnan AJ, Young VE, Gillard JH: Advances in noninvasive imaging for evaluating clinical risk and guiding therapy in carotid atherosclerosis. Expert Rev Cardiovasc Ther 2012, 10:37-53. 
18. Vancraeynest D, Pasquet A, Roelants V, Gerber BL, Vanoverschelde JL: Imaging the vulnerable plaque. J Am Coll Cardiol 2011, 57:1961-1979.

19. Johnson JM, Kennelly MM, Decesare D, Morgan S, Sparrow A: Natural history of asymptomatic carotid plaque. Arch Surg 1985, 120:1010-1012.

20. Reiter M, Effenberger I, Sabeti S, Mlekusch W, Schlager O, Dick P, Puchner S, Amighi J, Bucek RA, Minar E, Schillinger M: Increasing carotid plaque echolucency is predictive of cardiovascular events in high-risk patients. Radiology 2008, 248:1050-1055.

21. Sillesen $\mathrm{H}$ : Carotid artery plaque composition--relationship to clinical presentation and ultrasound B-mode imaging. Eur J Vasc Endovasc Surg 1995, 10:23-30.

22. Tegos TJ, Sohail M, Sabetai MM, Robless P, Akbar N, Pare G, Stansby G, Nicolaides AN: Echomorphologic and histopathologic characteristics of unstable carotid plaques. AJNR Am J Neuroradiol 2000, 21:1937-1944.

23. Sztajzel R, Momjian S, Momjian-Mayor I, Murith N, Djebaili K, Boissard G, Comelli M, Pizolatto G: Stratified gray-scale median analysis and color mapping of the carotid plaque: correlation with endarterectomy specimen histology of 28 patients. Stroke 2005, 36:741-745.

24. Nighoghossian N, Derex L, Douek P: The vulnerable carotid artery plaque: current imaging methods and new perspectives. Stroke 2005, 36:2764-2772.

25. Nordestgaard BG, Gronholdt ML, Sillesen H: Echolucent rupture-prone plaques. Curr Opin Lipidol 2003, 14:505-512.

26. Gronholdt ML, Nordestgaard BG, Bentzon J, Wiebe BM, Zhou J, Falk E, Sillesen $\mathrm{H}$ : Macrophages are associated with lipid-rich carotid artery plaques, echolucency on B-mode imaging, and elevated plasma lipid levels. J Vasc Surg 2002, 35:137-145.

27. Moreno PR, Purushothaman KR, Sirol M, Levy AP, Fuster V: Neovascularization in human atherosclerosis. Circulation 2006, 113:2245-2252.

28. Fleiner M, Kummer M, Mirlacher M, Sauter G, Cathomas G, Krapf R, Biedermann BC: Arterial neovascularization and inflammation in vulnerable patients: early and late signs of symptomatic atherosclerosis. Circulation 2004, 110:2843-2850.

29. Moreno PR, Purushothaman KR, Fuster V, Echeverri D, Truszczynska H, Sharma SK, Badimon JJ, O'Connor WN: Plaque neovascularization is increased in ruptured atherosclerotic lesions of human aorta: implications for plaque vulnerability. Circulation 2004, 110:2032-2038.

30. McCarthy MJ, Loftus IM, Thompson MM, Jones L, London NJ, Bell PR, Naylor AR, Brindle NP: Angiogenesis and the atherosclerotic carotid plaque: an association between symptomatology and plaque morphology. $J$ Vasc Surg 1999, 30:261-268.

31. Kumamoto M, Nakashima $Y$, Sueishi $K$ : Intimal neovascularization in human coronary atherosclerosis: its origin and pathophysiological significance. Hum Pathol 1995, 26:450-456.

32. Sluimer JC, Gasc JM, van Wanroij JL, Kisters N, Groeneweg M, Sollewijn Gelpke MD, Cleutjens JP, van den Akker LH, Corvol P, Wouters BG, Daemen MJ, Bijnens AP: Hypoxia, hypoxia-inducible transcription factor, and macrophages in human atherosclerotic plaques are correlated with intraplaque angiogenesis. J Am Coll Cardiol 2008, 51:1258-1265.

33. Feinstein SB: Contrast ultrasound imaging of the carotid artery vasa vasorum and atherosclerotic plaque neovascularization. J Am Coll Cardiol 2006, 48:236-243.

34. Faggioli GL, Pini R, Mauro R, Pasquinelli G, Fittipaldi S, Freyrie A, Serra C, Stella A: Identification of carotid 'vulnerable plaque' by contrastenhanced ultrasonography: correlation with plaque histology, symptoms and cerebral computed tomography. Eur J Vasc Endovasc Surg 2011, 41:238-248

35. Momjian-Mayor I, Baron JC: The pathophysiology of watershed infarction in internal carotid artery disease: review of cerebral perfusion studies. Stroke 2005, 36:567-577.

36. Siebler M, Nachtmann A, Sitzer M, Rose G, Kleinschmidt A, Rademacher J, Steinmetz $\mathrm{H}$ : Cerebral microembolism and the risk of ischemia in asymptomatic high-grade internal carotid artery stenosis. Stroke 1995, 26:2184-2186.

doi:10.1186/1471-2342-13-13

Cite this article as: Zhou et al: An assessment of the vulnerability of carotid plaques: a comparative study between intraplaque neovascularization and plaque echogenicity. BMC Medical Imaging 2013 13:13.

\section{Submit your next manuscript to BioMed Central and take full advantage of:}

- Convenient online submission

- Thorough peer review

- No space constraints or color figure charges

- Immediate publication on acceptance

- Inclusion in PubMed, CAS, Scopus and Google Scholar

- Research which is freely available for redistribution 